\title{
The influence of ageing on the incidence and site of trauma femoral fractures: a cross-sectional analysis
}

\author{
Shao-Chun $\mathrm{Wu}^{1+}$, Cheng-Shyuan Rau ${ }^{2 \dagger}$, Spencer C. H. Kuo ${ }^{3}$, Peng-Chen Chien ${ }^{3}$ and Ching-Hua Hsieh ${ }^{3 *}$ (D)
}

\begin{abstract}
Background: This study aimed to determine the influence of ageing on the incidence and site of femoral fractures in trauma patients, by taking the sex, body weight, and trauma mechanisms into account.

Methods: This retrospective study reviewed data from adult trauma patients aged $\geq 20$ years who were admitted into a Level I trauma center, between January 1, 2009 and December 31, 2016. According to the femoral fracture locations, 3859 adult patients with 4011 fracture sites were grouped into five subgroups: proximal type A $(n=1359)$, proximal type B $(n=1487)$, proximal type C $(n=59)$, femoral shaft $(n=640)$, and distal femur $(n=466)$ groups. A multivariate logistic regression analysis was applied to identify independent effects of the univariate predictive variables on the occurrence of fracture at a specific site. A two-dimensional plot was presented visually with age and the propensity score accounts for the risk of a fracture at a specific femoral site.
\end{abstract}

Results: This analysis revealed that older age was an independent variable that could positively predict the occurrence of proximal type A (OR [95\%Cl]: 1.03 [1.03-1.04], $p<0.001)$ and B fractures (1.02 [1.01-1.02], $p<0.001)$, and negatively predict the occurrence of proximal type $C(0.96[0.94-0.98], p<0.001)$, shaft $(0.95[0.95-0.96], p<0.001)$, and distal fractures (0.98 [0.98-0.99], $p<0.001)$.

Discussion: Using the propensity scores which account for the risk of a fracture in a specific femoral site, this study revealed that the older patients were at a higher risk of developing proximal type A and type B fractures, while a lower risk of developing fractures in the shaft and distal femur. This incidence of fracture site can largely be explained by agerelated factors, including a decrease in bone strength and falling being the most common mechanism of trauma in older patients.

Conclusions: This study revealed a difference in the involvement of age in the incidence of femoral fracture sites in the trauma patients.

Keywords: Femur, Fracture, Trauma, Weight, Obese, Fall, Osteoporosis, Age

\section{Introduction}

Femoral fractures are an injury commonly seen in the emergency room. According to an 11-year long population-based cohort study in Taiwan, the adjusted standard incidence rate of hip fracture is between 5.01 and 11.70 per million persons. As the longest bone in the human body, the femur is divided into several different parts including the head,

\footnotetext{
* Correspondence: m93chinghua@gmail.com

†Shao-Chun Wu and Cheng-Shyuan Rau contributed equally to this work.

${ }^{3}$ Department of Plastic Surgery, Kaohsiung Chang Gung Memorial Hospital,

Chang Gung University and College of Medicine, No.123, Ta-Pei

RoadNiao-Song District, Kaohsiung City 833, Taiwan

Full list of author information is available at the end of the article
}

neck, greater and lesser trochanters, shaft, and the distal condyles. Fractures can occur in any of these areas. The fracture site is determined by the force, the impact point, and how the forces are transmitted through the bone [1]. In addition, the fracture site of the femur may also be determined by the structure and strength of the bone. The site of femoral fracture can be categorized according to the Arbeitsgemeinschaft für Osteosynthesefragen (AO) classification as proximal femoral (type A: trochanteric; type B: neck; and type C: head), femoral shaft, and distal femoral fractures [2].

(c) The Author(s). 2019 Open Access This article is distributed under the terms of the Creative Commons Attribution 4.0 International License (http://creativecommons.org/licenses/by/4.0/), which permits unrestricted use, distribution, and reproduction in any medium, provided you give appropriate credit to the original author(s) and the source, provide a link to the Creative Commons license, and indicate if changes were made. The Creative Commons Public Domain Dedication waiver (http://creativecommons.org/publicdomain/zero/1.0/) applies to the data made available in this article, unless otherwise stated. 
Determination of the influence of age on the incidence of femoral fractures in any given part of the bone is complex, because many age-related factors, including gender, trauma mechanism, body weight, and bony density, would also have impact on the occurrence of the femoral fracture. The factors influencing femoral fracture site are interrelated and are not independent. For example, increasing age is associated with osteoporotic bone changes, which are believed to increase the rate of femoral fracture; falls occur more frequently in the elderly [3, 4] but traffic-related fractures caused by motorcycle or bicycle accidents occur more often in younger adults and the rate of its occurrence differs between genders $[4,5]$. In a fall accident, the force directly impacts the posterolateral aspect of the greater trochanter, but the impact point is not limited to only this site in a non-fall accident. Therefore, proximal type $A$ and $B$ fractures are predominant in falls, but in motorcycle accidents, femoral shaft fracture comprises the most common fracture site, followed by distal femoral fractures [4]. In addition, The distribution of impact force through the hip that is associated with falls from a standing height is greater than the average energy required to fracture an elderly hip but not that of a younger adult [6]. Furthermore, gender is another important risk factor that has influence on the occurrence of femoral fracture, as a sharp decline in bone mineral density (BMD) among women during transition from 5 th to 6th decade which signifies association of menopause with osteoporosis [7]. Obesity is another of the most important factor that determines possible osteoporotic change to a femur [8-10]. Previous studies have shown that the magnitude of traumatic impact force increases in proportion to body weight and thus would increase the incidence of fractures around the knee [11]. However, some studies report that obese patients have a lower rate of hip fracture [12-14], which may be due to increased cushioning of the bone by fat deposits over the trochanter and iliac wing areas $[15,16]$, and more importantly, increased bone density and less osteoporotic bone $[17,18]$.

Therefore, using the propensity scores which account for the risk of a fracture in a specific femoral site, this study aimed to determine the association of age with the site and incidence of femoral fracture in trauma patients, by taking the sex, body weight, and trauma mechanisms (fall and non-fall) into account.

\section{Methods}

\section{Ethics statement}

Ethical approval for this study was obtained from the institutional review board (IRB) of the Kaohsiung Chang Gung Memorial Hospital, a level I regional trauma center in southern Taiwan $[5,19,20]$ (reference number:
201800742B0). According to IRB regulations, the need for informed consent was waived.

\section{Study population}

This was a retrospective study and the work has been reported according to the guideline of Strengthening the Reporting of Cohort Studies in Surgery (STROCSS) [21]. This retrospective study reviewed data from 27,462 trauma patients registered between January 1, 2009 and December 31, 2016 (Fig. 1). The inclusion criteria required patients to be aged $\geq 20$ years and hospitalized for the treatment of femoral fracture following injury. Patients with incomplete data were excluded. The patient data that was retrieved included age; sex; mechanism of trauma; BMI (which was calculated as weight $(\mathrm{kg}) /$ height $\left.(\mathrm{m})^{2}\right)$. Patients were classified as obese (BMI of $\geq 30 \mathrm{~kg} / \mathrm{m}^{2}$ ), overweight (BMI of $<30$ but $\geq 25 \mathrm{~kg} / \mathrm{m}^{2}$ ), normal weight (BMI of $<25$ but $\geq 18.5 \mathrm{~kg} / \mathrm{m}^{2}$ ), and underweight (BMI of $<18.5 \mathrm{~kg} / \mathrm{m}^{2}$ ) based on the definition recommended by the World Health Organization $[22,23]$. Trauma patients were categorized as faller (fall from standing height) or non-faller (which included motor vehicle accidents, motorcycle accidents, bicycle accidents, and patients struck by/against an object). According to the femoral fracture locations, 3859 patients with 4011 fracture sites were grouped into five subgroups as patients with fracture of proximal type A $(n=1359)$, proximal type B $(n=1487)$, proximal type C $(n=59)$, femoral shaft $(n=640)$, and distal femur $(n=466)$.

\section{Statistical analysis}

Statistical analysis was performed using SPSS for Windows version 22 (IBM Corp., Armonk, NY, USA). For each subgroup of patients, the categorical variables of the patients were compared using a Pearson chi-squared test or Fishers exact test and presented as odds ratios (ORs) with 95\% confidence intervals (CIs). The continuous variables were estimated using Levene's test for homogeneity of variance and evaluated using one-way analysis of variance (ANOVA) with a Games-Howell post-hoc test to analyze the differences between the patients with or without femoral fracture at a specific site. Continuous data were expressed as mean \pm standard deviation. Multivariate logistic regression analysis was applied to identify independent effects of univariate predictive variables on the occurrence of fracture at a specific site. A $p$ value of $<0.05$ was determined to be statistically significant. To provide an illustration of the pattern of patient characteristics in relation to the risk of occurrence of a femur fractures at a specific site, the propensity score which account for the risk of a fracture in a specific femoral site was calculated. This generated a scalar value defined as the conditional probability of assignment to an event, given a vector of observed covariates [24, 25]. These propensity scores and the factor of age were 


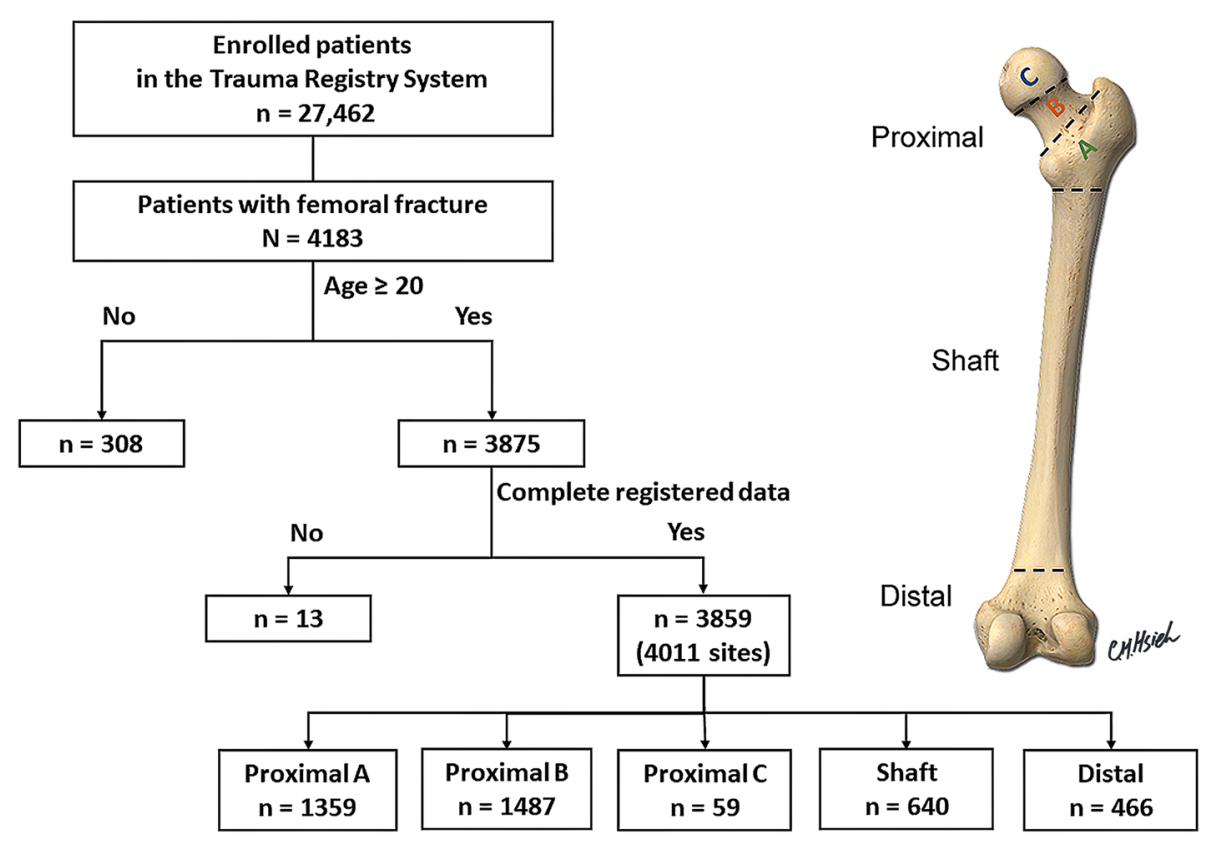

Fig. 1 A flow chart presenting the grouping of fracture sites among the hospitalized adult patients with traumatic femoral bone fractures, based on the $\mathrm{AO}$ classification. There are five femoral fracture sites: proximal type $\mathrm{A}$ (trochanteric), proximal type $\mathrm{B}$ (neck), proximal type $\mathrm{C}$ (head),

femoral shaft, and distal femur

presented visually in a two-dimensional plot using the Generic X-Y Plotting functions in the pROC package in $\mathrm{R}$ (version 3.3.3.).

\section{Results}

The association of patient characteristics with the site of femoral fractures

As shown in the Tables 1 and 2, the patients who sustained proximal type A and B fractures were significantly older (78 vs. 69 -years, $p<0.001$ and 76 vs. 70 -years, $p<$ 0.001 , respectively) than those that did not have femoral fracture in same location. In contrast, the patients who sustained proximal type C (35 vs. 73-years, $p<0.001$ ), shaft ( 44 vs. 75 -years, $p<0.001)$, and distal fractures $(60$ vs. 74 -years, $p<0.001$ ) were significantly younger than those who did not have a femoral fracture in same location. There were significantly fewer male patients with a proximal type B fracture $(p<0.001)$; however, there was a significant male predominance for proximal type $C$ fracture $(p<0.001)$ and shaft fractures $(p<0.001)$. More patients who were involved in a fall had proximal type A fractures than those who did not have a fall $(78.0 \%$ vs. $59.3 \%, p<0.001)$. In contrast, fewer patients with proximal type B $(22.0 \%$ vs. $57.0 \%, p<0.001), C(16.9 \%$ vs.

Table 1 The association of patient characteristics with proximal type A, B, and C femoral fractures

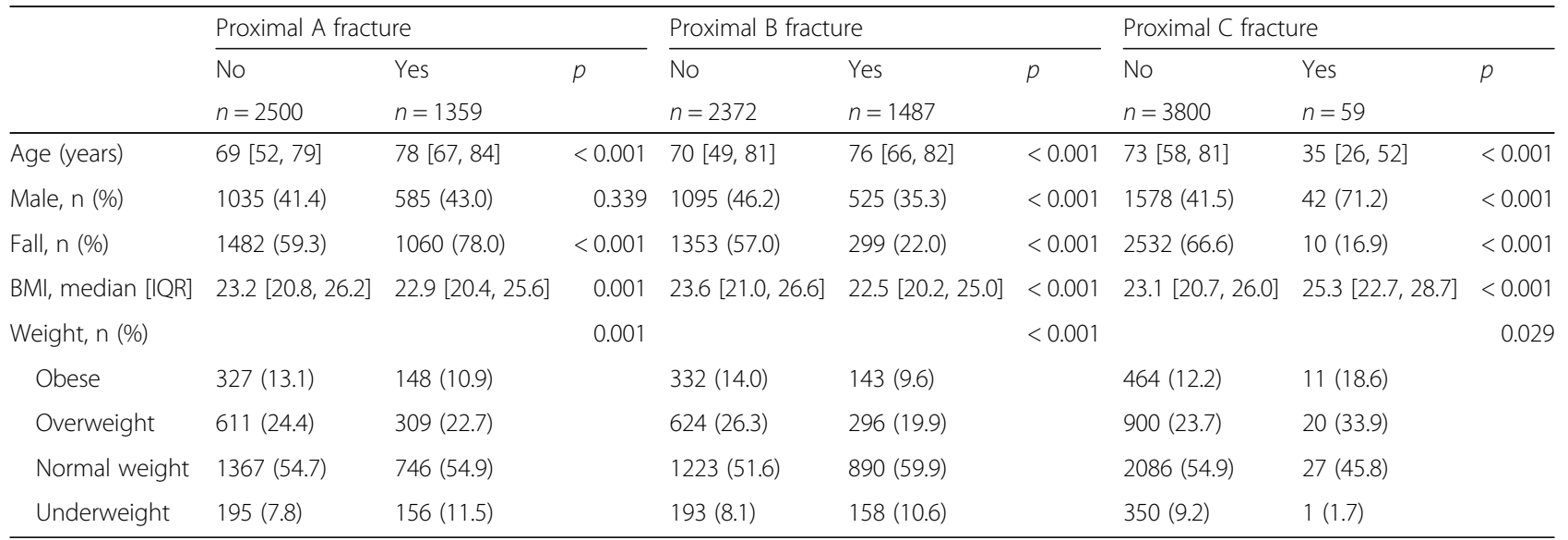


Table 2 The association of patient characteristics with femoral shaft and distal femoral fractures

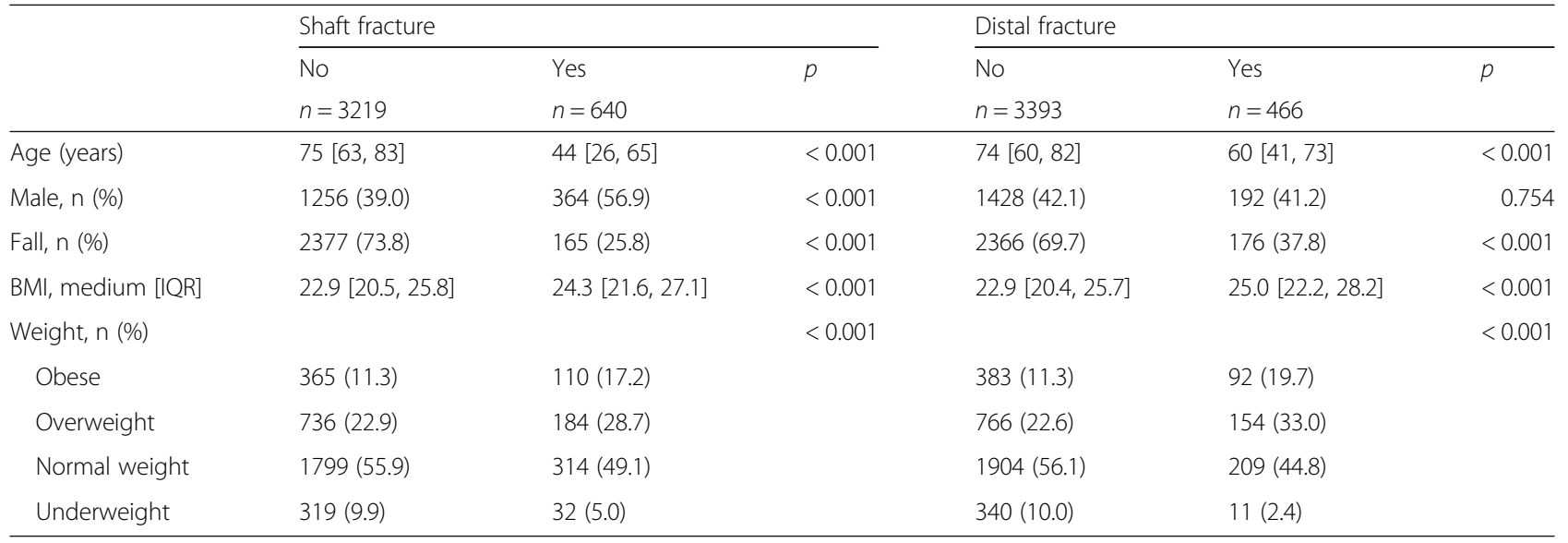

$B M I$ Body mass index, IQR Interquartile range

$66.6 \%, p<0.001)$, distal $(25.8 \%$ vs. $73.8 \%, p<0.001)$ and shaft $(37.8 \%$ vs. $69.7 \%, p<0.001)$ fractures had been involved in a fall than those non-fallers. Patients who had proximal type $\mathrm{A}$ and $\mathrm{B}$ fractures had a significantly lower BMI (22.9 vs. $23.2, p<0.001$ and 22.5 vs. $23.6, p<0.001$, respectively) than those who did not have a femoral fracture in same location; in contrast, patients who had proximal type $C$ ( 25.3 vs. $23.1, p<0.001)$, shaft ( 24.3 vs. $22.9, p<0.001)$ and distal fractures $(25.0$ vs. $22.9, p<0.001)$ had a significantly higher BMI than those who did not have a femoral fracture in same location.

\section{Independent variables of patient characteristics associated with sites of femoral fractures}

As shown in Table 3, multivariate logistic regression analysis was applied to identify the independent variables that were associated with the occurrence of femoral fracture at a specific site. This analysis revealed that older age was an independent variable that could positively predict the occurrence of proximal type A (OR [95\%CI]: $1.03[1.03-1.04], p<0.001)$ and $\mathrm{B}$ fractures (1.02 [1.01-1.02], $p<0.001)$, and negatively predict the occurrence of proximal type C (0.96 [0.94-0.98], $p<$ $0.001)$, shaft $(0.95[0.95-0.96], p<0.001)$, and distal fractures $(0.98$ [0.98-0.99], $p<0.001)$. In terms of proximal type A fractures, males had a $70 \%$ greater risk $(\mathrm{OR}=1.70)$, when compared to females, and those who had a fall had a $47 \%$ greater risk $(O R=1.47)$, when compared to non-fallers. In terms of proximal type B fractures, fallers had a $93 \%$ greater risk $(O R=1.93)$, when compared to non-fallers, but those who were obese had a $28 \%$ lower risk $(\mathrm{OR}=0.72)$ than those who were not obese. In terms of proximal type $\mathrm{C}$ and distal fractures, those who had a fall had a $63 \%$ lower risk $(\mathrm{OR}=0.37)$

Table 3 Variables applied to multivariate logistic regression analysis to identify the independent factors associated with the occurrence of femoral fracture at a specific site

\begin{tabular}{|c|c|c|c|c|c|c|c|c|c|}
\hline Fracture site & Proximal A & & & Proximal B & & & Proximal C & & \\
\hline Variables & coefficient & OR $(95 \% \mathrm{Cl})$ & $p$ & coefficient & OR $(95 \% \mathrm{Cl})$ & $p$ & coefficient & OR $(95 \% \mathrm{Cl})$ & $p$ \\
\hline Age & 0.03 & $1.03(1.03-1.04)$ & $<0.001$ & 0.02 & $1.02(1.01-1.02)$ & $<0.001$ & -0.04 & $0.96(0.94-0.98)$ & $<0.001$ \\
\hline Male & 0.53 & $1.70(1.46-1.98)$ & $<0.001$ & -0.11 & $0.90(0.78-1.04)$ & 0.15 & 0.39 & $1.48(0.83-2.77)$ & 0.20 \\
\hline Faller & 0.39 & $1.47(1.22-1.77)$ & $<0.001$ & 0.66 & $1.93(1.61-2.31)$ & $<0.001$ & -0.99 & $0.37(0.16-0.83)$ & 0.02 \\
\hline obese & -0.04 & $0.96(0.77-1.19)$ & 0.73 & -0.33 & $0.72(0.58-0.89)$ & $<0.001$ & 0.24 & $1.27(0.61-2.42)$ & 0.50 \\
\hline Intercept & -3.33 & $0.04(0.02-0.05)$ & $<0.001$ & -2.04 & $0.13(0.09-0.18)$ & $<0.001$ & -1.78 & $0.17(0.07-0.40)$ & $<0.001$ \\
\hline Fracture site & Shaft & & & Distal & & & & & \\
\hline Variables & coefficient & OR $(95 \% \mathrm{Cl})$ & $p$ & coefficient & OR $(95 \% \mathrm{Cl})$ & $p$ & & & \\
\hline Age & -0.05 & $0.95(0.95-0.96)$ & $<0.001$ & -0.02 & $0.98(0.98-0.99)$ & $<0.001$ & & & \\
\hline Male & -0.20 & $0.82(0.66-1.01)$ & 0.07 & -0.60 & $0.55(0.44-0.69)$ & $<0.001$ & & & \\
\hline Faller & -1.00 & $0.37(0.29-0.47)$ & $<0.001$ & -1.06 & $0.35(0.27-0.45)$ & $<0.001$ & & & \\
\hline obese & 0.28 & $1.32(1.00-1.74)$ & 0.05 & 0.53 & $1.70(1.30-2.20)$ & $<0.001$ & & & \\
\hline Intercept & 1.89 & 6.65 (4.62-9.62) & $<0.001$ & -0.18 & $0.84(0.58-1.21)$ & 0.35 & & & \\
\hline
\end{tabular}


than those non-fallers. Regarding distal fracture, males and fallers had a 45 and $65 \%$ lower risk $(\mathrm{OR}=0.55$ and 0.35 , respectively) than females and those non-fallers, respectively, but those obese patients had a $70 \%$ greater risk $(\mathrm{OR}=1.70)$ than those who were not obese.

\section{An illustration of the pattern of patient characteristics in relation to the risk of occurrence of a fracture}

The relationships between fracture risk patterns and patient characteristics in those who sustained proximal type A (Fig. 2) or B (Fig. 3) fractures are similar and revealed that, in these two fracture sites, older patients had a higher risk of fractures, the patients with a fall had a higher risk of sustaining a fracture, while those who were obese were at a lower risk of developing fractures in these sites. The incidence of proximal type A and B fractures increased with age both in the female and male patients.

The relationships between fracture risk patterns and patient characteristics in those who sustained a shaft (Fig. 4) or distal (Fig. 5) fracture are similar. The results are contrary to those observed for patients who had proximal type A or type B fractures. As noted in the illustrations, in the shaft and distal fracture sites, older patients and patients who had suffered a fall had a lower risk of sustaining these types of fracture, while those who were obese were at a higher risk of developing these fractures. The risk of developing shaft and distal femoral fractures decreased with age in both female and male patients. Furthermore, the fracture risk pattern for proximal type $C$ fractures (Fig. 6) was similar to that observed in those who had a shaft or distal fracture, however, the trend is less prominent in this case and is less obvious because there were only a small number of patients with a proximal type $C$ fractures $(n=59)$.

\section{Discussion}

This study revealed a difference in the involvement of age in the incidence of femoral fracture sites in the trauma patients. Older patients were at a higher risk of developing proximal type $\mathrm{A}$ and type $\mathrm{B}$ fractures, while a lower risk of developing fractures in the shaft and distal femur. This incidence of fracture site can largely be explained by age-related factors, including a decrease in bone strength and falling being the most common mechanism of trauma in older patients. In cases where trauma is caused by a fall, the force directly impacts the posterolateral aspect of the greater trochanter, making the femoral neck particularly vulnerable to fractures [26]. Fall has been reported to be the major cause of intracapsular neck and peritrochanteric fractures of the femur [27], which are closely associated with severe generalized bone loss, and account for a significant proportion of femoral fractures in the elderly [28, 29]. In obese patients, increased soft tissue padding around the hip attenuates the greater impact forces that result from falls and reduces the force transmitted to the bone $[15,16]$. In contrast, obese patients had a higher odds risk for shaft and distal femoral fractures in fall accidents [4]. In this type of scenario, the body weight associated with obesity would increase the impact force but provide less protection in the shaft and distal region of the femur.

Femoral shaft and distal fractures can occur in younger patients without any evidence of osteoporosis, usually as a result of a high-energy trauma such as a motor vehicle accident or motorcycle accident $[8,9,30,31]$. The impact of the energy transmitted to the bone is

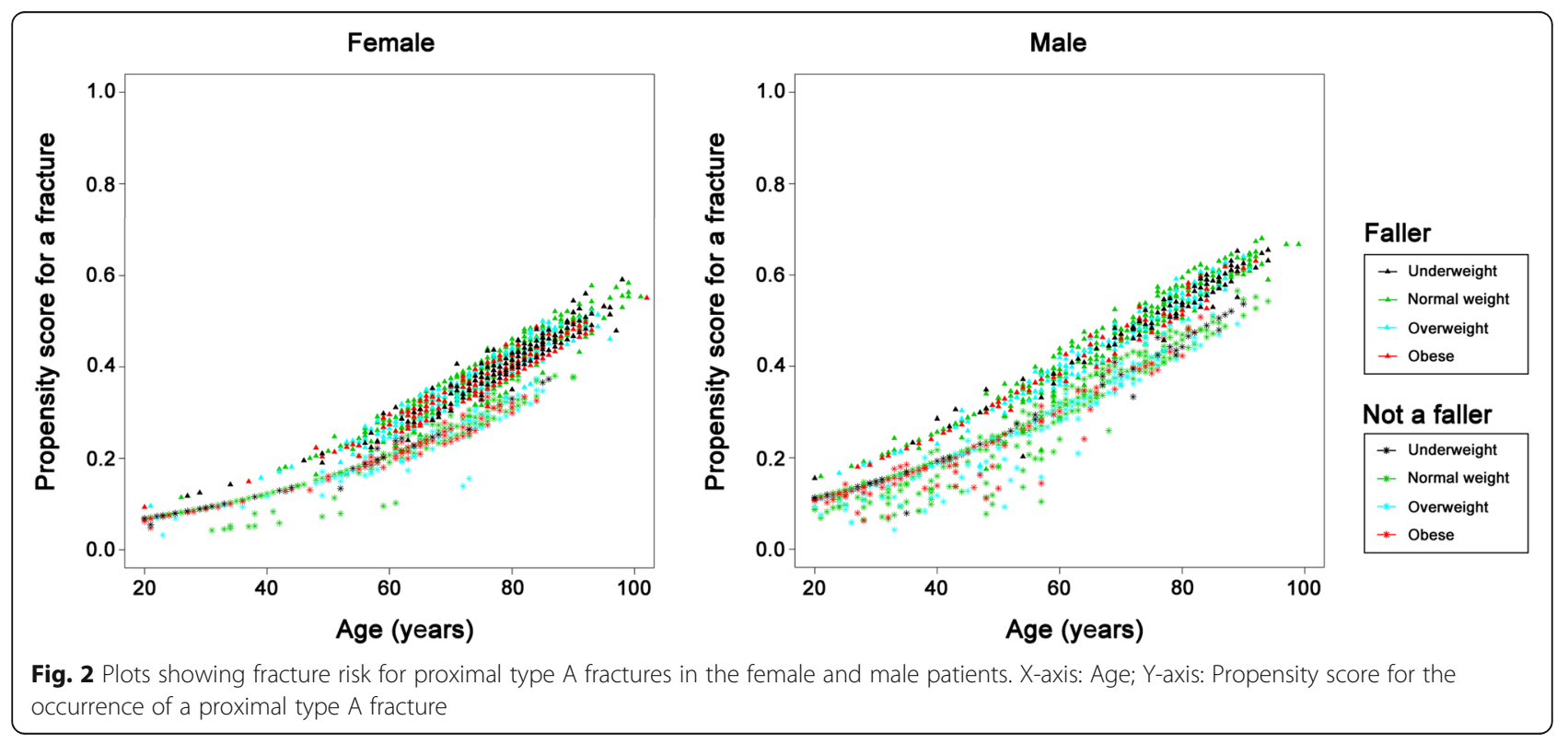




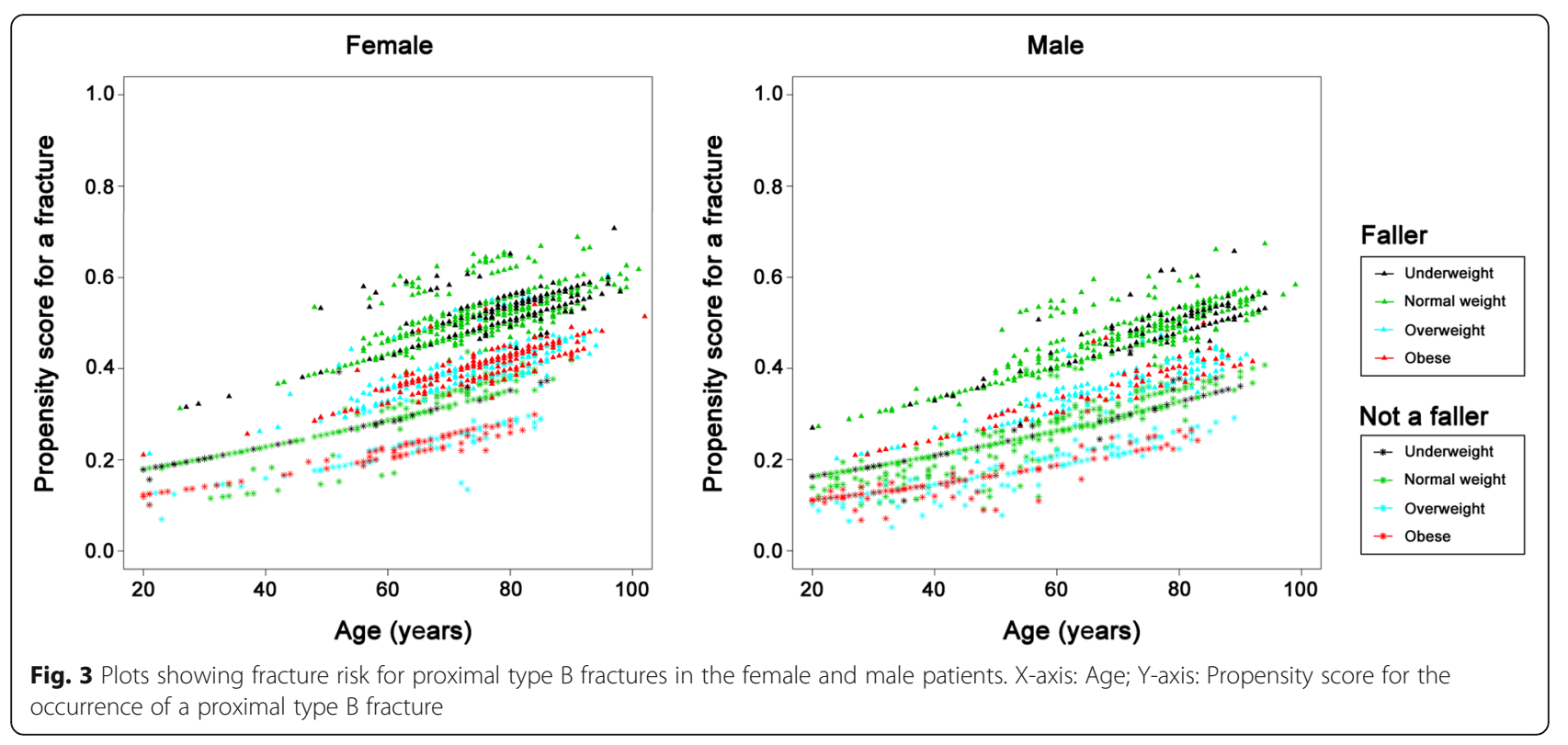

generally greater in traffic accidents than in fall accidents, and the point of impact to the femur is not limited to the greater trochanter, which commonly occurs in falls. In cases involving high-energy trauma to various sites of the femur, obesity does not reduce the impact, and may even increase the trauma by applying an unbearable load to the bone, as the magnitude of impact force increases in proportion to body weight. For example, it has been demonstrated that in motor vehicle accidents, an elevated BMI decreases the risks of injury in nearside impacts, but increases the risk of lower-extremity injury in frontal crashes $[15,16]$.

Increasing age has been reported to be associated with an increase in the incidence of proximal type A fractures in women and an increase in the incidence of proximal type $B$ and $C$ fractures in men [32]. In addition, previous studies have demonstrated that the proportion of trochanteric fractures increased with age in female patients but not in male patients [30, 33, 34]. This phenomenon is believed to be due to more pronounced bone loss in older female patients compared to males, which makes female subjects more susceptible to peritrochanteric fractures than intracapsular fractures [30, 33, 34]. In this study, we did not find a difference between genders, and, as patients increased in age, the trend for both female and male patients to sustain a fracture in a given femoral site was similar. While the incidence of proximal type A and $B$ fractures increased with age in both genders, the

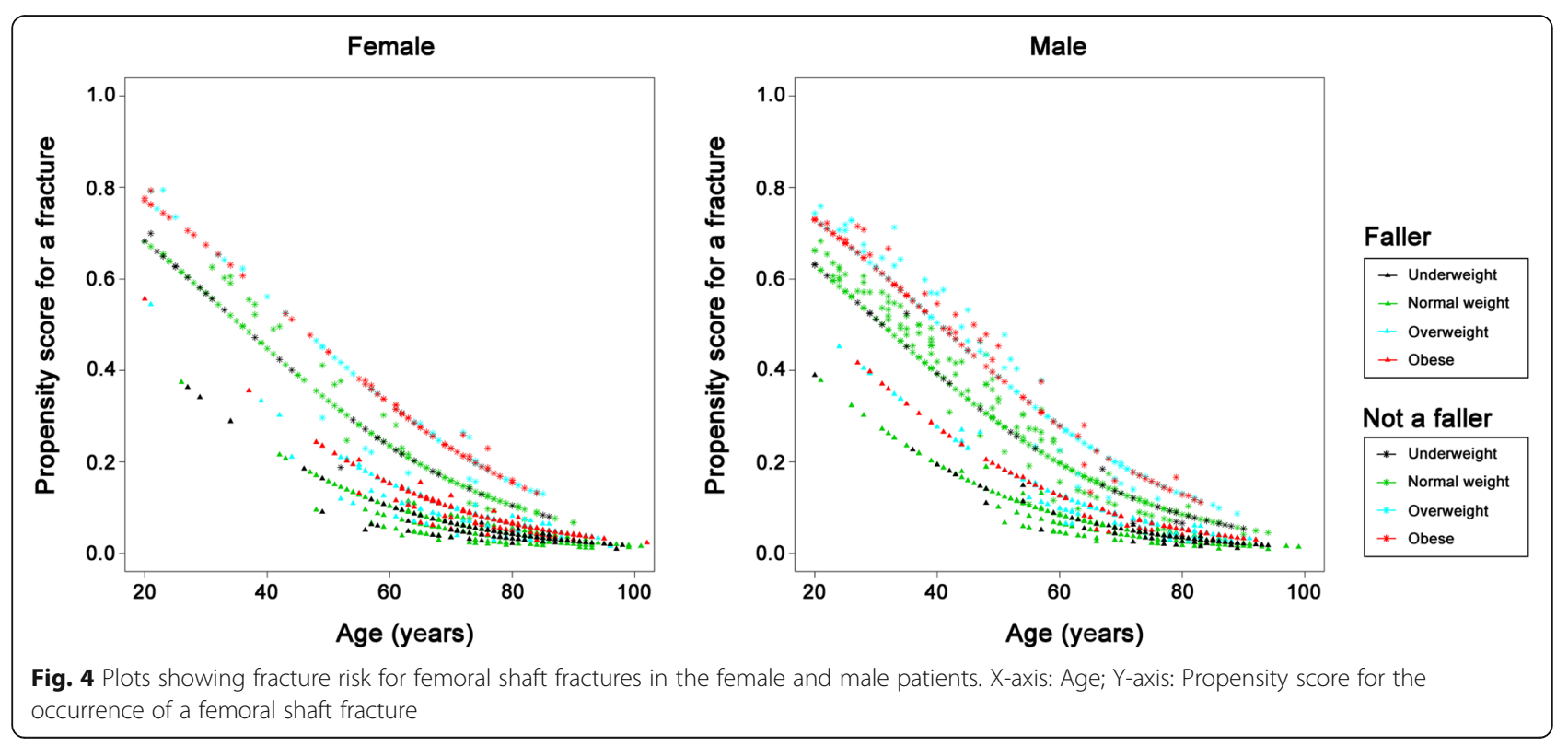




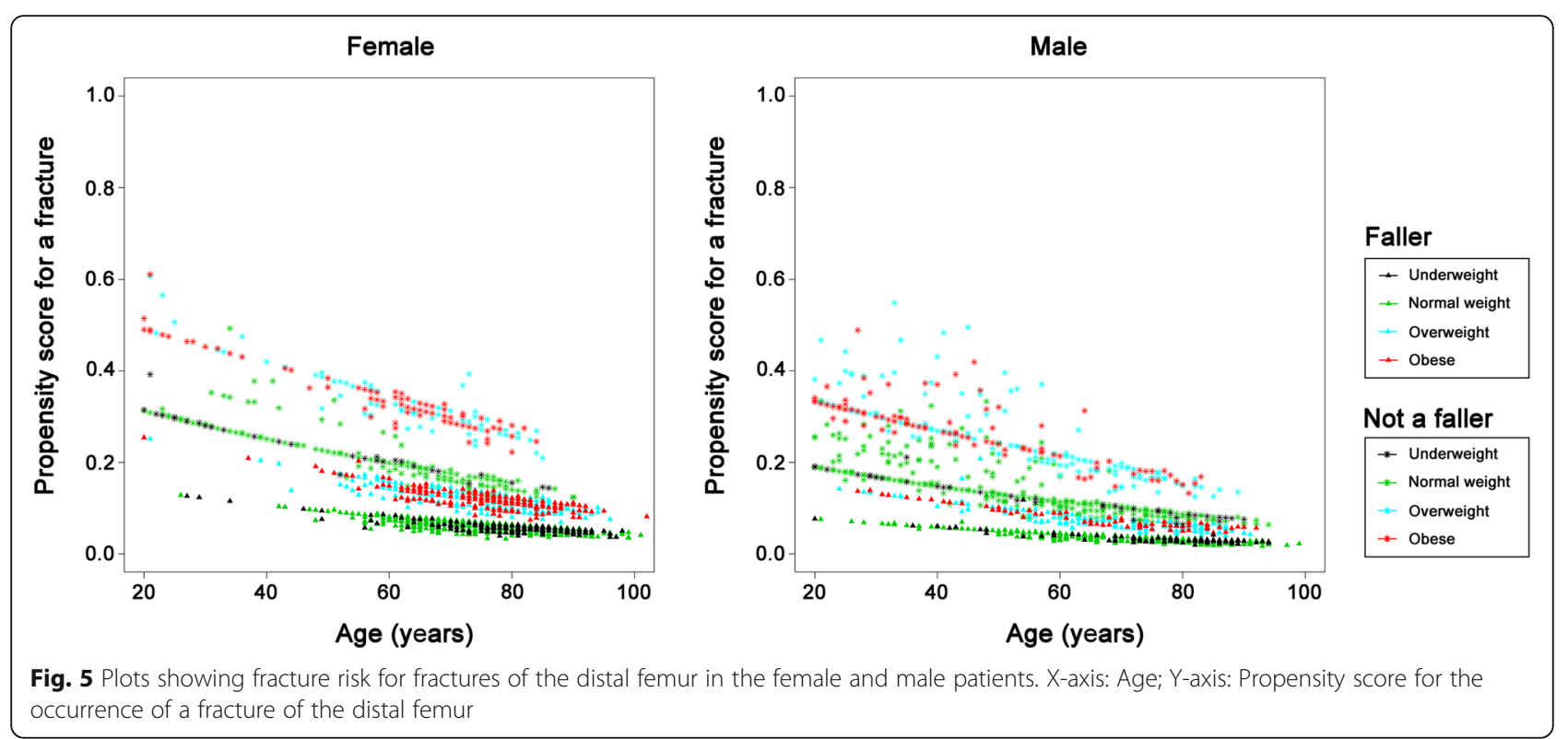

incidence of shaft and distal femoral fractures decreased with age in both genders. Female gender is independently associated with a higher rate of a proximal type A fractures and a lower rate of distal fractures.

In this study, the head of the femur was the part that was the least likely to be fractured, probably because it is relatively hidden in the acetabulum, therefore would only fracture if an impact force was transmitted from the femur to the hemi pelvis and acetabulum. Although the fracture risk pattern in proximal type $\mathrm{C}$ fractures was similar to that observed in those who had a shaft or distal fracture, the trend is less clear due to the small number of patients with this type of fracture. This makes it harder to draw conclusions about fractures at this site.
This study has some limitations that need to be acknowledged. First, the retrospective design of the study may have resulted in a selection bias. Second, the impact force, impact location and the protection method were unknown during the trauma accident, especially considering these factors may vary widely during a high-speed motorcycle accidents. Third, the lack of information regarding the status of osteoporosis may lead to a bias in the analysis. Fourth, this study does not cover a number of risk factors, which have been identified for as risk factors for fracture including medication use such as glucocorticoids [35, 36] or bisphosphonates [37], previous fragility fractures [38], and smoking and alcohol consumption [39], which may result in a bias in the

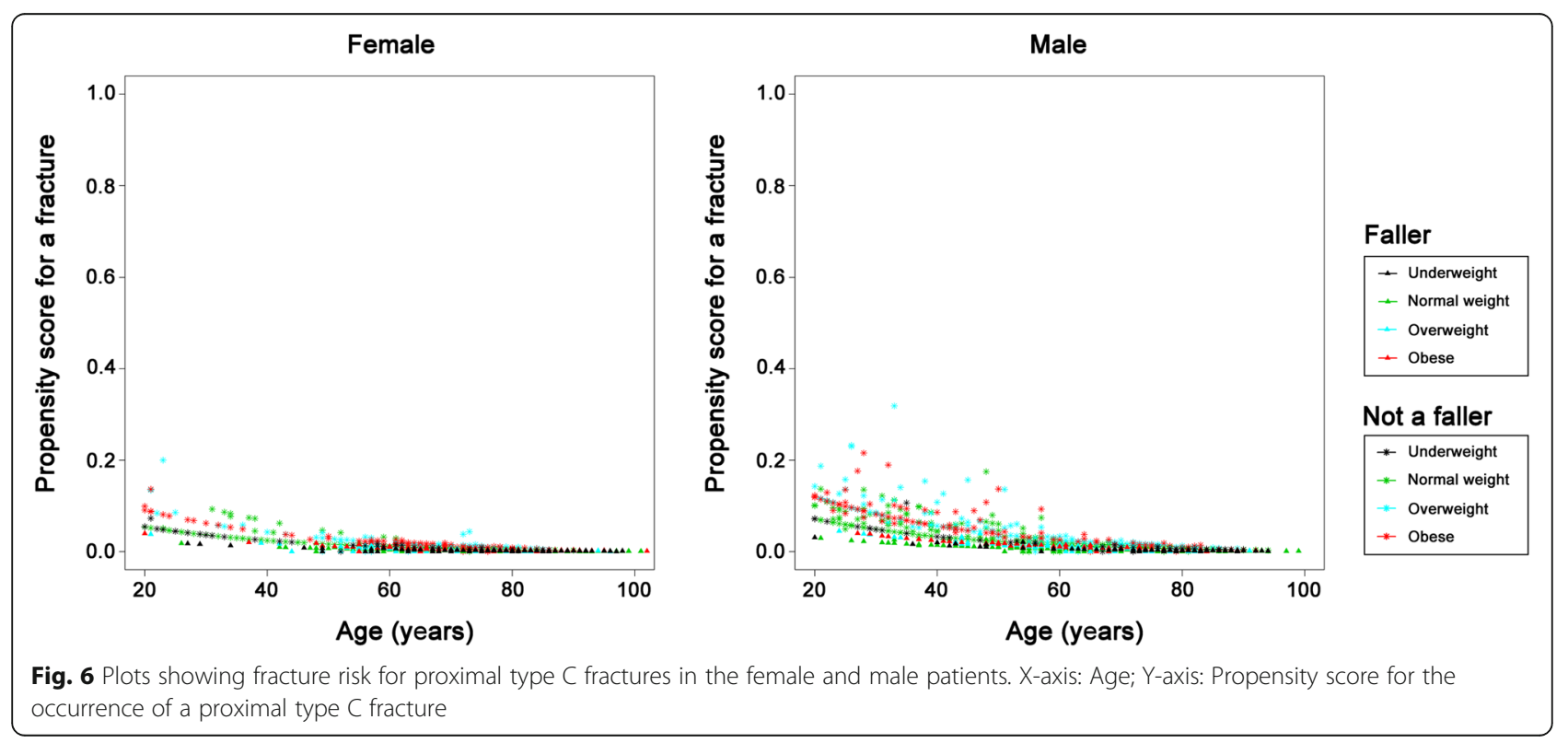


analysis. At last, the population included in this study is limited to a single urban trauma center in southern Taiwan, which means that the results may be different in other regions.

\section{Conclusion}

This study revealed that the fracture risk for developing proximal type A and B fractures increases with aging in a similar pattern, which is in contrast to the fracture risk pattern for shaft or distal fractures.

\section{Abbreviations}

ANOVA: One-way analysis of variance; AO: Arbeitsgemeinschaft für Osteosynthesefragen; BMD: bone mineral density; Cl: Confidence intervals; IRB: Institutional review board; OR: Odds ratio; STROCSS: Strengthening the Reporting of Cohort Studies in Surgery

\section{Acknowledgements}

We would like to thank the Biostatistics Center, Kaohsiung Chang Gung Memorial Hospital for assisting with statistical analyses.

\section{Authors' contributions}

S-CW wrote the manuscript; C-SR edited the tables and proof-read the manuscript; SCHK reviewed the literature; P-CC performed the statistical analyses; $\mathrm{C}-\mathrm{HH}$ designed the study and contributed to the analysis and interpretation of data. All authors read and approved the final manuscript.

\section{Funding}

This research was supported by a grant from CDRPG8H0012 to $\mathrm{CHH}$. The funding did not play any roles in the study design, in the collection, interpretation and analysis of data, and in the writing of manuscript.

\section{Availability of data and materials}

The data are not publicly available due the privacy of patients included but are available from the corresponding author on reasonable request for academic research purpose.

\section{Ethics approval and consent to participate}

This study was approved by the institutional review board (IRB) of the Kaohsiung Chang Gung Memorial Hospital with a reference number: 201800742B0. According to IRB regulations, the need for informed consent was waived.

\section{Consent for publication}

Not Applicable

\section{Competing interests}

The authors declare that they have no competing interests.

\section{Author details}

'Department of Anesthesiology, Kaohsiung Chang Gung Memorial Hospital, Chang Gung University and College of Medicine, Kaohsiung 83301, Taiwan. 2Department of Neurosurgery, Kaohsiung Chang Gung Memorial Hospital, Chang Gung University and College of Medicine, Kaohsiung 83301, Taiwan. ${ }^{3}$ Department of Plastic Surgery, Kaohsiung Chang Gung Memorial Hospital, Chang Gung University and College of Medicine, No.123, Ta-Pei RoadNiao-Song District, Kaohsiung City 833, Taiwan.

\section{Received: 17 April 2019 Accepted: 30 August 2019}

Published online: 05 September 2019

\section{References}

1. Gregory JS, Aspden RM. Femoral geometry as a risk factor for osteoporotic hip fracture in men and women. Med Eng Phys. 2008;30(10):1275-86.

2. SN MM, Koch P, Schatzker J. The comprehensive classification of fractures of the long bones. Berlin: Springer; 1990
3. Rau CS, Lin TS, Wu SC, Yang JC, Hsu SY, Cho TY, Hsieh CH. Geriatric hospitalizations in fall-related injuries. Scand J Trauma Resusc Emerg Med. 2014;22:63.

4. Chang MW, Liu HT, Huang CY, Chien PC, Hsieh HY, Hsieh CH. Location of Femoral Fractures in Patients with Different Weight Classes in Fall and Motorcycle Accidents: A Retrospective Cross-Sectional Analysis. Int J Environ Res Public Health. 2018;15(6):1082.

5. Hsieh CH, Hsu SY, Hsieh HY, Chen YC. Differences between the sexes in motorcycle-related injuries and fatalities at a Taiwanese level I trauma center. Biom J. 2017:40(2):113-20.

6. Hayes WC, Myers ER, Morris JN, Gerhart TN, Yett HS, Lipsitz LA. Impact near the hip dominates fracture risk in elderly nursing home residents who fall. Calcif Tissue Int. 1993;52(3):192-8.

7. Singh M, Arora S, Kaur A, Ghildiyal S, Kumar R. Patterns of age- and sex-related variations in bone mineral density of lumbar spine and Total femur: a retrospective diagnostic laboratory-based study. J Midlife Health. 2018;9(3):155-61.

8. Chen CC, Rau CS, Wu SC, Kuo PJ, Chen YC, Hsieh HY, Hsieh CH. Association of osteoporosis self-assessment tool for asians (OSTA) score with clinical presentation and expenditure in hospitalized trauma patients with femoral fractures. Int J Environ Res Public Health. 2016:13(10):995.

9. Rau CS, Wu SC, Kuo PJ, Chen YC, Chien PC, Hsieh HY, Hsieh CH. Epidemiology of bone fracture in female trauma patients based on risks of osteoporosis assessed using the osteoporosis self-assessment tool for asians score. Int J Environ Res Public Health. 2017;14(11):1380.

10. Koh LK, Sedrine WB, Torralba TP, Kung A, Fujiwara S, Chan SP, Huang QR, Rajatanavin R, Tsai KS, Park HM, et al. A simple tool to identify asian women at increased risk of osteoporosis. Osteoporos Int. 2001; 12(8):699-705.

11. Rupp JD, Flannagan CA, Kuppa SM. Injury risk curves for the skeletal knee-thigh-hip complex for knee-impact loading. Accid Anal Prev. 2010:42(1):153-8.

12. Beck TJ, Petit MA, Wu G, LeBoff MS, Cauley JA, Chen Z. Does obesity really make the femur stronger? BMD, geometry, and fracture incidence in the women's health initiative-observational study. J Bone Miner Res. 2009:24(8):1369-79.

13. Bouxsein ML, Szulc P, Munoz F, Thrall E, Sornay-Rendu E, Delmas PD. Contribution of trochanteric soft tissues to fall force estimates, the factor of risk, and prediction of hip fracture risk. J Bone Miner Res. 2007;22(6):825-31.

14. FitzGerald G, Boonen S, Compston JE, Pfeilschifter J, LaCroix AZ, Hosmer DW Jr, Hooven FH, Gehlbach SH. Differing risk profiles for individual fracture sites: evidence from the global longitudinal study of osteoporosis in women (GLOW). J Bone Miner Res. 2012;27(9):1907-15.

15. Rupp JD, Flannagan CA, Leslie AJ, Hoff CN, Reed MP, Cunningham RM. Effects of BMI on the risk and frequency of AIS 3+ injuries in motor-vehicle crashes. Obesity (Silver Spring). 2013;21(1):E88-97.

16. Carter PM, Flannagan CA, Reed MP, Cunningham RM, Rupp JD. Comparing the effects of age, BMI and gender on severe injury (AIS 3+) in motorvehicle crashes. Accid Anal Prev. 2014;72:146-60.

17. Kato I, Toniolo P, Zeleniuch-Jacquotte A, Shore RE, Koenig KL, Akhmedkhanov A, Riboli E. Diet, smoking and anthropometric indices and postmenopausal bone fractures: a prospective study. Int J Epidemiol. 2000;29(1):85-92.

18. Looker AC, Flegal KM, Melton LJ 3rd. Impact of increased overweight on the projected prevalence of osteoporosis in older women. Osteoporos Int. 2007;18(3):307-13.

19. Hsieh CH, Liu HT, Hsu SY, Hsieh HY, Chen YC. Motorcycle-related hospitalizations of the elderly. Biom J. 2017;40(2):121-8.

20. Hsieh $\mathrm{CH}$, Chen YC, Hsu SY, Hsieh HY, Chien PC. Defining polytrauma by abbreviated injury scale $>/=3$ for a least two body regions is insufficient in terms of short-term outcome: a cross-sectional study at a level I trauma center. Biom J. 2018:41(5):321-7.

21. Agha RA, Borrelli MR, Vella-Baldacchino M, Thavayogan R, Orgill DP. The STROCSS statement: strengthening the reporting of cohort studies in surgery. Int J Surg. 2017;46:198-202.

22. Clugston GA, de Onis M, Eveleth $P$, Kramer M, Sizonenko P, Tuomilehto J, Villar J. Physical status: the use and interpretation of anthropometry. Report of a WHO expert committee. World Health Organ Tech Rep Ser. 1995;854:1452.

23. Akram DS, Astrup AV, Atinmo T, Boissin JL, Bray Ga, Carroll KK, Chitson P, Chunming C, Dietz WH, Hill JO, et al. Obesity: preventing and managing the 
global epidemic. Report of a WHO consultation. World Health Organ Tech Rep Ser. 2000;894(i-xii):1-253.

24. Feng P, Zhou XH, Zou QM, Fan MY, Li XS. Generalized propensity score for estimating the average treatment effect of multiple treatments. Stat Med. 2012;31(7):681-97.

25. Rubin DB. Estimating causal effects from large data sets using propensity scores. Ann Intern Med. 1997;127(8 Pt 2):757-63.

26. Keyak JH, Skinner HB, Fleming JA. Effect of force direction on femoral fracture load for two types of loading conditions. J Orthop Res. 2001; 19(4):539-44.

27. Anyaehie UE, Ejimofor OC, Akpuaka FC, Nwadinigwe CU. Pattern of femoral fractures and associated injuries in a Nigerian tertiary trauma Centre. Niger J Clin Pract. 2015;18(4):462-6.

28. Lindner T, Kanakaris NK, Marx B, Cockbain A, Kontakis G, Giannoudis PV. Fractures of the hip and osteoporosis: the role of bone substitutes. J Bone Joint Surg Br. 2009;91(3):294-303.

29. Cauley JA. Osteoporosis: fracture epidemiology update 2016. Curr Opin Rheumatol. 2017;29(2):150-6.

30. Lamb JN, Panteli M, Pneumaticos SG, Giannoudis PV. Epidemiology of pertrochanteric fractures: our institutional experience. Eur I Trauma Emerg Surg. 2014;40(3):225-32.

31. Rau CS, Wu SC, Chen YC, Chien PC, Hsieh HY, Kuo PJ, Hsieh CH. Stressinduced hyperglycemia in diabetes: a cross-sectional analysis to explore the definition based on the trauma registry data. Int J Environ Res Public Health 2017;14(12):1527.

32. Tanner DA, Kloseck M, Crilly RG, Chesworth B, Gilliland J. Hip fracture types in men and women change differently with age. BMC Geriatr. 2010;10:12.

33. Karagas MR, Lu-Yao GL, Barrett JA, Beach ML, Baron JA. Heterogeneity of hip fracture: age, race, sex, and geographic patterns of femoral neck and trochanteric fractures among the US elderly. Am J Epidemiol. 1996;143(7):677-82.

34. Yoon BH, Lee YK, Kim SC, Kim SH, Ha YC, Koo KH. Epidemiology of proximal femoral fractures in South Korea. Arch Osteoporos. 2013;8:157.

35. Buehring B, Viswanathan R, Binkley N, Busse W. Glucocorticoid-induced osteoporosis: an update on effects and management. J Allergy Clin Immunol. 2013;132(5):1019-30.

36. Amiche MA, Albaum JM, Tadrous M, Pechlivanoglou P, Levesque LE, Adachi JD, Cadarette SM. Fracture risk in oral glucocorticoid users: a Bayesian metaregression leveraging control arms of osteoporosis clinical trials. Osteoporos Int. 2016;27(5):1709-18.

37. Black DM, Abrahamsen B, Bouxsein ML, Einhorn T, Napoli N. Atypical femur fractures - review of epidemiology, relationship to bisphosphonates, prevention and clinical management. Endocr Rev. 2018;40:333.

38. Ojo F, Al Snih S, Ray LA, Raji MA, Markides KS. History of fractures as predictor of subsequent hip and nonhip fractures among older Mexican Americans. J Natl Med Assoc. 2007;99(4):412-8.

39. Levine JP. Pharmacologic and nonpharmacologic management of osteoporosis. Clin cornerstone. 2006:8(1):40-53.

\section{Publisher's Note}

Springer Nature remains neutral with regard to jurisdictional claims in published maps and institutional affiliations.

Ready to submit your research? Choose BMC and benefit from:
- fast, convenient online submission
- thorough peer review by experienced researchers in your field
- rapid publication on acceptance
- support for research data, including large and complex data types
- gold Open Access which fosters wider collaboration and increased citations
- maximum visibility for your research: over 100M website views per year
At BMC, research is always in progress.
Learn more biomedcentral.com/submissions

